\title{
COBERTURA VACINAL EM ADOLESCENTES NO BRASIL: O DESAFIO DE UM GIGANTE
}

\section{ARTIGO DE REVISÃO}

FERNANDES, Catiane Raquel Sousa ${ }^{1}$

COSTA, Gabriela Oliveira Parentes $\mathrm{Da}^{2}$

OLIVEIRA, Danielle Priscilla Sousa ${ }^{3}$

LOPES, Michelle Kerin ${ }^{4}$

LIMA, Cícera Jaqueline Ferreira de ${ }^{5}$

${ }_{1}^{1}$ Mestrado em saúde e comunidade (UFPI), especialista em oncologia (UESPI), especialista em docência do ensino superior (IESM), especialista em Enfermagem Neonatal com Habilitação em Uti (IESM).

2 Especialização em andamento em Enfermagem Em Centro Cirúrgico E Central De Materiais. Especialização em andamento em Docência para 0 ensino superior. Especialização em Urgência e Emergência. Graduação em andamento em CST em Podologia. Graduação em Enfermagem.

3 Mestrado profissional em andamento em Programa de Pós-Graduação em Educação Profissional e Tecnológica - ProfEPT. Especialização em Urgência e Emergência. Graduação em Enfermagem.

${ }^{4}$ Especialização em andamento em Enfermagem em Centro Cirúrgico e Material Esterilizado. Graduação em Enfermagem.

${ }^{5}$ Especialização em andamento em Auditoria Em Saúde. Graduação em andamento em Enfermagem. 
JANSEN, Ricardo Clayton Silva ${ }^{6}$

FERNANDES, Catiane Raquel Sousa. Et al. Cobertura vacinal em adolescentes no Brasil: 0 desafio de um gigante. Revista Científica Multidisciplinar Núcleo do Conhecimento. Ano 05, Ed. 10, Vol. 20, pp. 21-35. Outubro de 2020. ISSN: 24480959, Link de acesso: https://www.nucleodoconhecimento.com.br/saude/coberturavacinal

\section{RESUMO}

Estudo descritivo analítico sobre a produção científica sobre a cobertura vacinal dos adolescentes no Brasil, utilizando-se método da revisão integrativa através de pesquisa nas bases de dados Pubmed Central, LILACS e ADOLEC. A amostra selecionada foi de 07 artigos, que foram inferidos quali e quantitativamente. Como conclusão obteve-se que há cobertura vacinal satisfatórios para adolescentes de 10 a 14 anos e porcentagem reduzida para os adolescentes de 15 a 19 anos. Conclui-se que há uma lacuna na CV dos adolescentes devido a desinformação ou as estratégias utilizadas pelo $\mathrm{PNI}$, nesta faixa não serem contextualizadas para este público, havendo necessidade de aprofundamentos de estratégias eficazes para a faixa de 15 a 19 anos.

Palavras-Chave: Vacinação, adolescentes, cobertura vacinal, Brasil.

\section{INTRODUÇÃO}

No final do século $X X$ iniciou-se a preocupação com a cobertura vacinal do público adolescente, devido às metas vacinais da rotina dos países atingirem números inferiores à meta vacinal de 95\%, preconizada pela Organização Mundial de Saúde (OMS) para população de 10 a 19 anos (PAHO, 2012).

\footnotetext{
${ }^{6}$ Mestrado em Biodiversidade, Ambiente e Saúde. Especialização em andamento em Pós-Graduação Em Centro-Cirúrgico E Central De Material. Especialização em andamento em Segurança Do Trabalho. Graduação em Enfermagem.
} 
Atualmente no Brasil, estão disponíveis para o adolescente as vacinas: Hepatite B (VHB), Dupla adulto (dT) e Triplice Viral (SCR), para as adolescentes além das anteriores, encontra-se a disposição a vacina contra o Papiloma vírus humano (HPV $6,11,18)$.

Por ocasião da não vacinação durante a infância os adolescentes de ambos os sexos devem ser também, vacinados contra a febre amarela (FA), devendo todos os registros vacinais serem preferivelmente registrados no cartão de vacina do adolescente e Sistema de Informação do Programa Nacional de Imunização (Si-PNI) (BRASIL, 2015).

Os programas de vacinação constituem uma ação de saúde preventiva eficiente, se bem executado, pode revelar bons resultados em curto prazo e com menos custo para o país. No Brasil o Programa Nacional de Imunização (PNI) é regulamentado pela lei 6259/75 e decreto 78231/76. (BRASIL, 2014).

Ao completar 40 anos em 2006 o PNI brasileiro comemorou resultados positivos, pois, internacionalmente desponta como exemplo de política pública bem sucedida, devido a estratégias diferenciadas de vacinação e capacidade de mobilização social para adesão à vacinação nas campanhas e principalmente pelo vultoso número de salas de vacinação de rotina, além da informatização do registro de vacinados. (SILVA JúNIOR, 2013)

A descentralização e articulação integrada das ações desenvolvidas pelo PNI diminuem as desigualdades sociais e regionais diante da vacinação, pois a torna acessível a todos os brasileiros, exemplo disso é a eliminação de doenças infecciosas como Sarampo e Rubéola e controle de doenças como Meningites e influenza do tipo b. (DOMINGUES; TEIXEIRA; CARVALHO, 2013).

A Cobertura vacinal no Brasil tem índices elevados, porém, não uniformes, pois diferem por faixa etária e por níveis socioeconômicos, havendo necessidade de homogeneizar com imunização em massa, principalmente nos grupos vulneráveis. 
Em relação à cobertura vacinal apesar do avanço, sobretudo quando comparado à década de 80 e 90, segundo Francisco et. al. (2015), o público adolescente de 10 a 14 anos mantém os elevados índices de vacinação já nas faixas de 15 a 19 anos a proporção de abandono torna-se maior para vacinas multidoses como Hepatite $B$, mostrando-se de relevância o estudo sobre a produção bibliográfica em relação a cobertura vacinal dos adolescentes no Brasil.

\section{MATERIAIS E MÉTODOS}

O estudo é descritivo analítico com abordagem qualitativa e quantitativa, através de análise de artigos científicos com o desfecho de interesse.

Os artigos utilizados no estudo foram coletados de abril a maio de 2016, estabelecendo-se como parâmetro as produções dos anos de 2011 a 2015, nas bases de dados virtuais, tais como: as bases da Literatura Latino-Americana e do Caribe em Ciências da Saúde (LILACS) , Biblioteca virtual em Saúde do adolescente (ADOLEC) e Biblioteca Nacional de Medicina dos Estados Unidos (Pubmed Central $P M C)$, elencando-se para este estudo a questão norteadora: Qual a produção científica sobre a cobertura vacinal dos adolescentes no Brasil?

Dessa indagação procederam-se as etapas para elaboração da revisão integrativa sendo identificados os artigos, após a pesquisa nas bases de dados, com leitura exploratória, foram escolhidos artigos , disponíveis para leitura na integra, em português ou inglês que melhor se adequassem ao tema de interesse, excluindo-se documentos institucionais, projetos de intervenção e artigos com cobertura vacinal em idosos, adultos e crianças.

Posteriormente a seleção dos artigos para o estudo, realizou-se leituras e análises dos textos e para melhor compreensão elaborou-se um instrumento contendo identificação do artigo: título do trabalho, revista de publicação, ano, objetivos, resultados encontrados, conclusão além dos descritores utilizados (MASCARENHAS, 2016; GOMES, 2016; RODRIGUES, 2016). 
$\mathrm{Na}$ composição da amostra utilizou-se como termos mesh: mass imunization, mass vaccination, adolescent e Brazil, e por tratar-se de um tema nacional mas de relevância mundial, utilizou-se os termos dos descritores em saúde (Decs): cobertura vacinal, imunização, vacinação, adolescentes e Brasil. Realizou-se buscas subsequentes utilizando-se termos booleanos com o descritor cobertura vacinal, fazendo combinações com o elenco de todos os descritores .

Após análise elegeu-se para o estudo 32 artigos que abordavam a cobertura vacinal no Brasil, sendo 26 artigos científicos, 01 projeto de intervenção e 05 informes técnicos. Dos 26 artigos selecionados para amostra após releitura observou-se que havia predominância dos estudos sobre cobertura vacinal divergentes nas faixas da população de 10 a 19 anos, destacando-se 07 artigos com características relevantes para o estudo.

Após coleta de dados procedeu-se a leitura minuciosa focando no conjunto das principais informações que as mesmas continham, buscando-se a essência de cada estudo, seguindo-se a partir das singularidades dos artigos, a organização em tabelas e gráfico realizados nos programas Excel e Word 2010, para melhor compreensão das inferências qualitativas e quantitativas.

\section{RESULTADO E DISCUSSÃO}

Os índices de cobertura vacinal (CV) estão diretamente relacionados com a proporção de abandono (PA). O indivíduo encontra-se com cobertura vacinal completa quando se encontra com esquema vacinal adequado de acordo com calendário vacinal preconizado. (BRASIL, 2014).

Há o consenso entre os autores de que antes dos 20 anos existe heterogeneidade nas CV; sendo os seguimentos de 15 a 19 anos os que apresentam menores índices, havendo necessidade de estratégias vacinais que contemple as peculiaridades desse público. (FREITAS; OKANO; PEREIRA, 2011). 
A criação de um modelo matemático requer conhecimento prévio da realidade do cotidiano do $\mathrm{PNI}$, e configura como ferramenta epidemiológica pouco utilizada, devido algumas obscuridades em epidemiologia, ainda assim, é possível estabelecer medidas estatísticas que apontem a idade mais adequada para reforço de vacinas multidoses, a exemplo da hepatite B, como apontado no estudo de Freitas; Okano e Pereira (2011), a idade correta para realização do reforço seria a idade de 12 anos.

Gráfico 1. Distribuição dos artigos quanto aos principais descritores (mesh e Decs) utilizados, Teresina - PI - 2016.

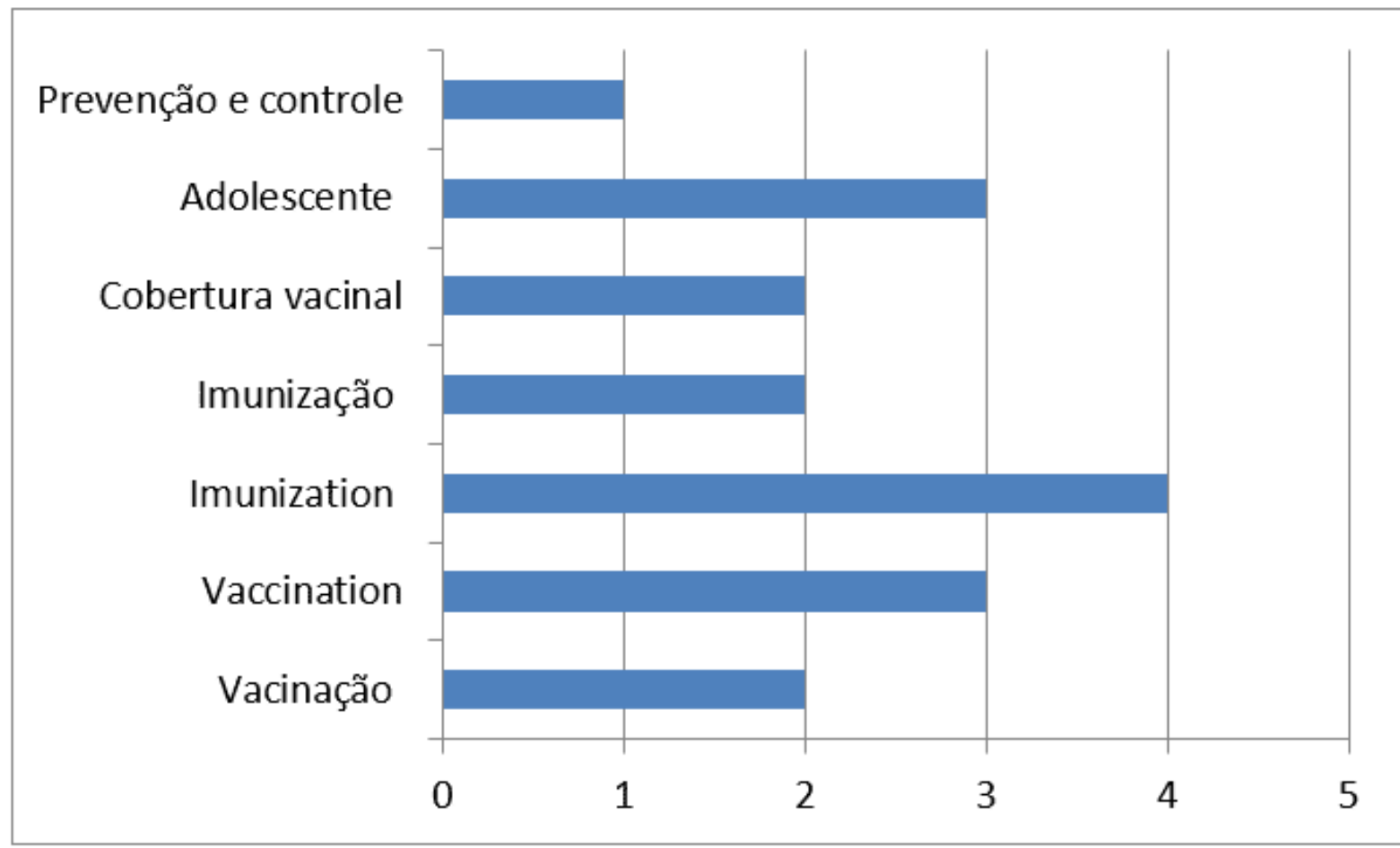

Fonte: pesquisa direta.

Os termos vacinação e imunização estão em destaque como descritores dos trabalhos, ainda que se trate de estabelecer uma prevenção primária poucos artigos relacionam imunização ou vacinação com cobertura vacinal, cabendo à autora fazer essa correlação durante a leitura dos artigos.

A saúde do adolescente apesar de incipiente, se comparadas às outras áreas da medicina, tem tido destaque pelos estudos nas faixas de 11 a 14 anos, ainda 
permanecendo a incógnita sobre a saúde dos adolescentes na faixa de 15 a 19 anos (tabela 1). No Brasil a cobertura vacinal apesar dos esforços do Ministério da Saúde (MS) para desmitificar a lacuna que há na faixa de 10 a 19 anos, ainda persiste baixos índices de CV , principalmente na faixa de 15 a 19 anos. No estudo de Bueno; Matijasevich (2011) este grupo atingiu no máximo 66\% da CV contra hepatite B em todos os municípios do Estado do Rio Grande do Sul.

Tabela 1. Caracterização dos artigos científicos quanto ao método, ano de publicação e local do estudo - Teresina, PI - Brasil - 2016.

\begin{tabular}{|c|c|c|c|c|c|}
\hline Autor & $\begin{array}{l}\text { Local/ } \\
\text { ano }\end{array}$ & $\begin{array}{l}\text { Periódico de } \\
\text { publicação/an } \\
\text { o }\end{array}$ & $\begin{array}{l}\text { Idioma } \\
\text { publicad } \\
\text { o }\end{array}$ & Método & Amostra \\
\hline $\begin{array}{l}\text { Freitas, } \\
\text { Okano, } \\
\text { Pereira }\end{array}$ & $\begin{array}{l}\text { São Paul } \\
\text { o }\end{array}$ & $\begin{array}{l}\text { Rev. Saud. } \\
\text { Publ. } 2011\end{array}$ & Inglês & $\begin{array}{l}\text { Estatístico } \\
\text { com } \\
\text { abordagem } \\
\text { realística. }\end{array}$ & Não \\
\hline $\begin{array}{l}\text { Bueno, } \\
\text { matigasevic } \\
\text { h }\end{array}$ & $\begin{array}{l}\text { Rio } \\
\text { Grande } \\
\text { do Sul }\end{array}$ & $\begin{array}{l}\text { Epidemiol. } \\
\text { Serv. Saúde } \\
2011\end{array}$ & $\begin{array}{l}\text { Portuguê } \\
\text { S }\end{array}$ & $\begin{array}{l}\text { Estudo } \\
\text { ecológico } \\
\text { analítico }\end{array}$ & Não \\
\hline $\begin{array}{l}\text { Domingues; } \\
\text { Teixeira }\end{array}$ & Brasil & $\begin{array}{l}\text { Epidemiol. } \\
\text { Serv. Saúde } \\
2013\end{array}$ & $\begin{array}{l}\text { Portuguê } \\
\text { s }\end{array}$ & $\begin{array}{l}\text { Ecológico } \\
\text { descritivo }\end{array}$ & Não \\
\hline Pereira et.al & $\begin{array}{l}\text { Belo } \\
\text { Horizonte }\end{array}$ & $\begin{array}{l}\text { Rev.Med.Min } \\
\text { as Gerais } \\
2013\end{array}$ & Inglês & $\begin{array}{l}\text { Estudo } \\
\text { epidemiológic } \\
0 \quad \text { por } \\
\text { conglomerad } \\
0\end{array}$ & $\begin{array}{l}210 \\
\text { adolescente } \\
\mathrm{s}\end{array}$ \\
\hline $\begin{array}{l}\text { Francisco } \\
\text { et.al }\end{array}$ & $\begin{array}{l}\text { Campina } \\
\mathrm{s}\end{array}$ & $\begin{array}{l}\text { Rev. Bras. } \\
\text { Epidemiol. } \\
2015\end{array}$ & $\begin{array}{l}\text { Portuguê } \\
\text { S }\end{array}$ & $\begin{array}{l}\text { Transversal } \\
\text { de base } \\
\text { populacional }\end{array}$ & $\begin{array}{l}702 \\
\text { adolescente } \\
\mathrm{s}\end{array}$ \\
\hline
\end{tabular}




\begin{tabular}{|c|c|c|c|c|c|}
\hline $\begin{array}{l}\text { Domingues } \\
\text {; Teixeira }\end{array}$ & Brasil & $\begin{array}{lr}\text { Rev. } & \text { Inst. } \\
\text { Med. } & \text { Hosp. } \\
\text { São } & \text { Paulo } \\
2012 & \end{array}$ & Inglês & $\begin{array}{l}\text { Estudo } \\
\text { descritivo } \\
\text { exploratório } \\
\text { de cunho } \\
\text { ecológico }\end{array}$ & Não \\
\hline $\begin{array}{l}\text { Francisco } \\
\text { et al }\end{array}$ & $\begin{array}{l}\text { São } \\
\text { Paulo }\end{array}$ & $\begin{array}{l}\text { Cad. Saúde } \\
\text { Pública RJ } \\
2013\end{array}$ & $\begin{array}{l}\text { Portuguê } \\
\text { S }\end{array}$ & $\begin{array}{l}\text { Transversal } \\
\text { de base } \\
\text { populacional }\end{array}$ & $\begin{array}{l}778 \\
\text { mulheres } \\
\text { em idade } \\
\text { fértil }\end{array}$ \\
\hline
\end{tabular}

Fonte: Pesquisa direta.

Tabela 2. Distribuição dos artigos científicos quando aos objetivos e principais resultados encontrados, Teresina - PI, 2016.

\begin{tabular}{|c|c|c|c|}
\hline Autores & Título & Objetivos & $\begin{array}{l}\text { Principais } \\
\text { Resultados } \\
\text { encontrados }\end{array}$ \\
\hline $\begin{array}{l}\text { Freitas, } \\
\text { Okano, } \\
\text { Pereira(2011) }\end{array}$ & $\begin{array}{l}\text { Pertussis booster } \\
\text { vaccine for } \\
\text { adolescents and } \\
\text { young adults in São } \\
\text { Paulo, Brazil. }\end{array}$ & $\begin{array}{l}\text { Desenvolver um } \\
\text { modelo estatístico } \\
\text { para melhorar a CV } \\
\text { para coqueluche. } \\
\text { Atingir possíveis } \\
\text { estratégias de } \\
\text { reforço para } \\
\text { coqueluche. }\end{array}$ & $\begin{array}{l}\text { O modelo proposto } \\
\text { com maior índice } \\
\text { para adesão a DTP } \\
\text { seria aos } 12 \text { anos. } \\
\text { Associar a dT com P } \\
\text { diminui a incidência } \\
\text { de coqueluche nos } \\
\text { adolescentes. }\end{array}$ \\
\hline $\begin{array}{l}\text { Bueno; } \\
\text { matijasevich } \\
(2011)\end{array}$ & $\begin{array}{l}\text { Avaliação da } \\
\text { cobertura vacinal } \\
\text { contra hepatite B nos } \\
\text { menores de } 20 \text { anos } \\
\text { em municípios do }\end{array}$ & $\begin{array}{l}\text { Avaliar cobertura da } \\
\text { vacina contra o vírus } \\
\text { da hepatite B na } \\
\text { população menor de } \\
20 \text { anos de idade }\end{array}$ & $\begin{array}{l}\text { Municípios menores } \\
\text { de } 20 \text { mil habitantes } \\
\text { tem cobertura acima } \\
\text { de } 100 \% \text {. Há } \\
\text { heterogeneidade. }\end{array}$ \\
\hline
\end{tabular}




\begin{tabular}{|c|c|c|c|}
\hline & $\begin{array}{lll}\text { Estado do } & \text { Rio } \\
\text { Grande do } & \text { Sul, } \\
\text { Brasil. } & & \end{array}$ & $\begin{array}{l}\text { nos } 22 \text { municípios } \\
\text { da terceira } \\
\text { coordenadoria } \\
\text { regional de Saúde } \\
\text { do Estado do Rio } \\
\text { Grande do Sul no } \\
\text { ano de } 2007 \text {. }\end{array}$ & $\begin{array}{l}\text { O grupo de } 11 \text { a } 14 \\
\text { anos teve } \mathrm{CV}<95 \% \\
\text { apenas em } 1 \\
\text { município, os demais } \\
\text { oscilaram de } 42 \text { a } \\
50 \% \\
\text { O grupo de } 15 \text { a } 19 \\
\text { anos atingiu no } \\
\text { máximo } 66 \% \text { em } \\
\text { todos os municípios, } \\
\text { com uma } \\
\text { heterogeneidade de } \\
90 \% \text {. }\end{array}$ \\
\hline $\begin{array}{l}\text { Domingues; } \\
\text { Teixeira }\end{array}$ & $\begin{array}{l}\text { Coberturas vacinais } \\
\text { e } \\
\text { imunopreveníveis no } \\
\text { Brasil } \\
\text { 2012:avanços } \\
\text { desafios } \\
\text { Programa nacional } \\
\text { de imunizações }\end{array}$ & $\begin{array}{l}\text { Descrever as CV; } \\
\text { Proporção de } \\
\text { abandono (PA) e } \\
\text { homogeneidade de } \\
\text { CV e incidência de } \\
\text { doenças } \\
\text { imunopreveníveis } \\
\text { selecionadas no } \\
\text { Brasil. }\end{array}$ & 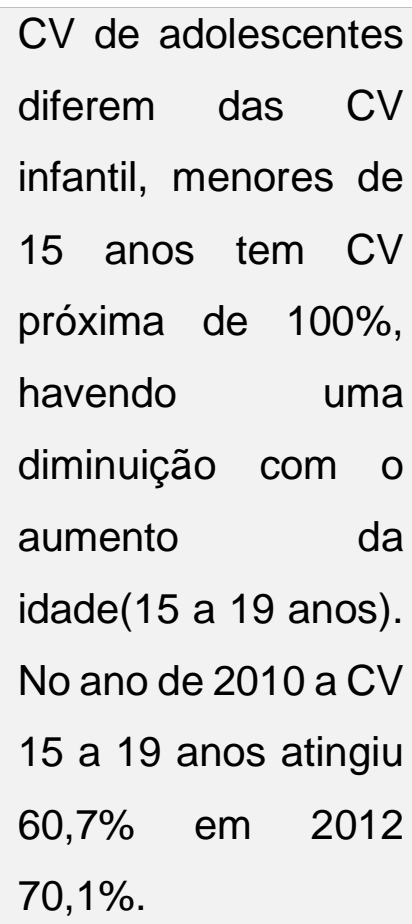 \\
\hline $\begin{array}{l}\text { Pereira et.al } \\
\text { (2013) }\end{array}$ & $\begin{array}{l}\text { Vaccination } \\
\text { coverage among } \\
\text { adolescentes in the } \\
\text { áreas surrounding } \\
\text { the cachoeirinha }\end{array}$ & $\begin{array}{l}\text { Identificar os } \\
\text { adolescentes com } \\
\text { esquema vacinal } \\
\text { completo }\end{array}$ & $\begin{array}{l}\text { Os pais conhecem } \\
\text { sobre rubéola } \\
\text { tétano, mas } \\
\text { desconhece hepatite } \\
\text { B com IST(infecção }\end{array}$ \\
\hline
\end{tabular}




\begin{tabular}{|c|c|c|c|}
\hline & $\begin{array}{l}\text { health center in the } \\
\text { northe astern region } \\
\text { of Belo Horizonte - } \\
\text { MG }\end{array}$ & $\begin{array}{l}\text { Analisar com o } \\
\text { adolescente, pais ou } \\
\text { responsáveis } \\
\text { compreendem a } \\
\text { vacinação para } \\
\text { doenças } \\
\text { imunopreveníveis. }\end{array}$ & $\begin{array}{l}\text { sexualmente } \\
\text { transmissível). } \\
\text { Pais desconhecem } \\
\text { ou sabem pouco } \\
\text { sobre vacina ou } \\
\text { doenças preveníveis } \\
\text { por vacinação } \\
\text { (tétano, rubéola } \\
\text { hepatite B) } \\
\text { Adolescentes de BH } \\
\text { conhecem sobre } \mathrm{FA} \\
\text { e sabem a } \\
\text { necessidade de } \\
\text { vacinação (surto em } \\
\text { 2002). }\end{array}$ \\
\hline $\begin{array}{l}\text { Domingues; } \\
\text { Teixeira } \\
\text { (2012) }\end{array}$ & $\begin{array}{l}\text { National } \\
\text { immunization } \\
\text { Program: } \\
\text { vaccination, } \\
\text { compliance and } \\
\text { Pharmacovigilance. }\end{array}$ & $\begin{array}{l}\text { Narrar as vacinas } \\
\text { disponíveis no Brasil } \\
\text { Estudar a CV no } \\
\text { Brasil } \\
\text { Discutir os eventos } \\
\text { adversos pós } \\
\text { vacinais(EAPV) } \\
\text { como fator para não } \\
\text { adesão. }\end{array}$ & 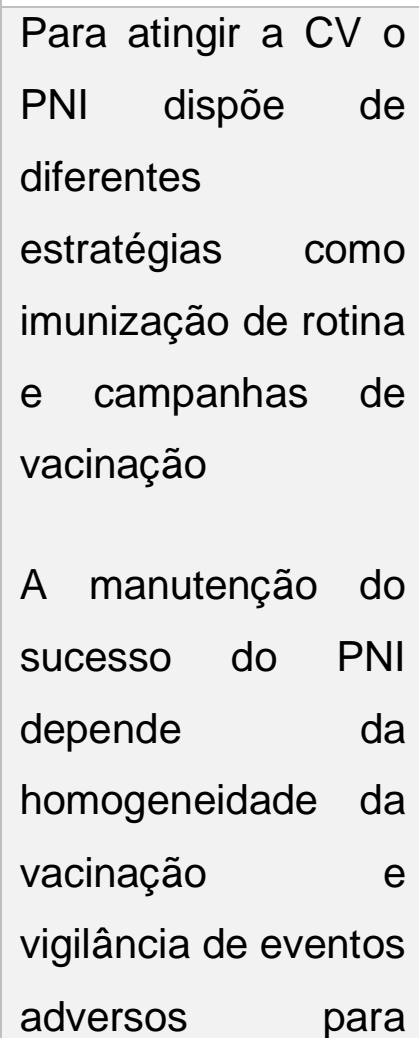 \\
\hline
\end{tabular}




\begin{tabular}{|c|c|c|c|}
\hline & & & $\begin{array}{l}\text { intervir em tempo } \\
\text { hábil. }\end{array}$ \\
\hline $\begin{array}{l}\text { Francisco } \\
\text { et.al } \\
(2013)\end{array}$ & $\begin{array}{l}\text { Vacinação contra } \\
\text { rubéola em mulheres } \\
\text { em idade reprodutiva } \\
\text { no município de } \\
\text { campinas, São } \\
\text { Paulo, Brasil. }\end{array}$ & $\begin{array}{lr}\text { Avaliar } & \text { a } \\
\text { prevalência } & \text { de } \\
\text { vacinação } & \text { contra } \\
\text { rubéola } & \text { em } \\
\text { mulheres; } & \\
\text { Identificar fatores } \\
\text { associados } \\
\text { motivos da não } \\
\text { adesão. }\end{array}$ & $\begin{array}{l}\text { A prevalência de } \\
\text { rubéola em } \\
\text { adolescentes é } \\
\text { menor(75\%) } \\
\text { As mulheres } \\
\text { adegaram idade } \\
\text { insuficiente" para ser } \\
\text { vacinada, falta } \\
\text { evidenciando informação e } \\
\text { de desconhecimento } \\
\text { sobre a oferta de } \\
\text { vacina e capanhas. }\end{array}$ \\
\hline $\begin{array}{l}\text { Francisco } \\
\text { et.al } \\
(2015)\end{array}$ & $\begin{array}{lr}\begin{array}{lr}\text { Vacinação } \\
\text { hepatite B }\end{array} & \text { em } \\
\text { adolescentes } & \\
\text { residentes } & \text { em } \\
\text { campinas, } & \text { São } \\
\text { Paulo, Brasil } & \end{array}$ & 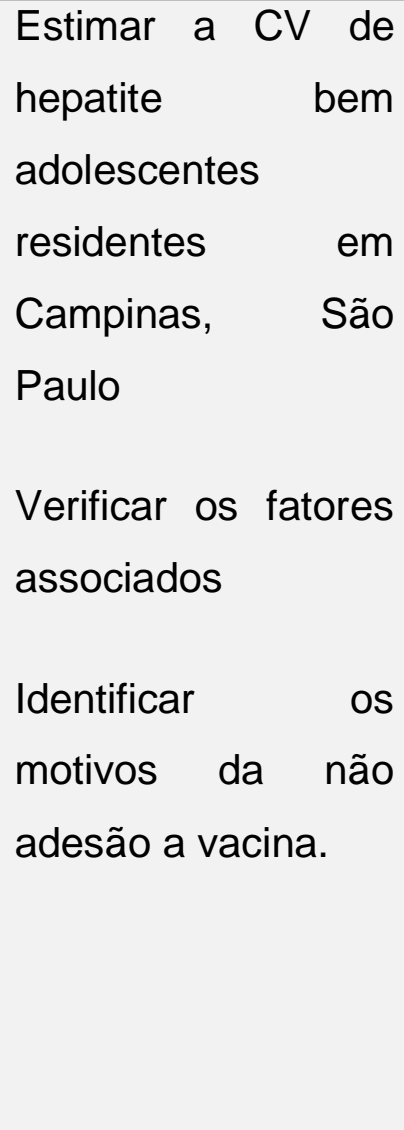 & $\begin{array}{lr}\text { Adolescentes não } & \text { eram } \\
\text { vacinados de } & \text { do } \\
\text { procedentes localidades, } \\
\text { outras } \\
\text { orientação de } \\
\text { profissional } \\
\text { saúde foi positiva, } \\
\text { apesar } \\
\text { desconhecer } \\
\text { necessidade das } 3 \\
\text { doses representar } \\
63 \% \text { entre os que } \\
\text { não } \\
\text { vacinados, } \\
\text { apontaram } \\
\text { esquecimento }\end{array}$ \\
\hline
\end{tabular}


desconhecimento

das 3 doses em $25 \%$

e $13 \%$ não por não considerar a vacina necessária

Fonte: pesquisa direta, tradução dos autores.

Francisco et. al. (2013) elenca a cobertura vacinal em grupo específico como as mulheres em idade reprodutiva, posteriormente em seu trabalho 2015 voltou-se para o público adolescente, ratificando que há necessidade de aprofundar estudos sobre cobertura vacinal nas faixas de 15 a 19 anos.

Os autores apontam o empenho da equipe de Saúde da Família (eSF) como primordial para a captação precoce dos adolescentes por ocasião da primeira visita ao posto ou através da escola. (PEREIRA et. al., 2013; FRANCISCO et. al., 2015).

Em 2008 o governo federal Brasileiro criou o Programa de saúde na escola (PSE), com a ideia de dar uma resolutividade para alguns problemas específicos para o público adolescente e oportunizar a vigilância em saúde no âmbito escolar. (BRASIL, 2009).

A captação precoce e o processo educacional são evidenciados em todos os artigos, direta ou indiretamente, sobretudo quando enfatizam a atuação dos profissionais de saúde na promoção da saúde, sendo que um artigo descreve como positiva a orientação sobre imunização e vacinação, ainda aponta; que esta informação embora bem sucedida, não contempla o esquema de vacinas multidoses, como hepatite $B$; assim; o adolescente pode estar recebendo a informação de forma incompleta (BRASIL, 2013; FRANCISCO et. al., 2013; 2015).

O protagonismo dos profissionais de saúde é secundário frente ao desafio dos gestores em saúde para homogeneizar as CV no Brasil, ainda que denotada nos estudos a importância desses profissionais, não apontam de fato estratégias que 
possam favorecer esse processo de educação em saúde, sobretudo para o público adolescente.

A renda não configura como fator limitante para vacinação, orientação positiva dos profissionais mostrou-se ineficaz se trabalhada isoladamente, neste sentido os pais ou responsáveis podem ampliar a CV nos adolescentes de 15 a 19 anos.

O estudo de Francisco et. al. (2013) evidenciou que os pais de 40 a 49 anos, desconhecem a hepatite B como Infecção sexualmente transmissível (IST), e não orientam a vacinação para os filhos por não considerar importante para adolescentes, fato este também observado em estudos sobre cobertura vacinal em gestantes adolescentes, sugerindo que deve-se dar um enfoque familiar as práticas de educação em saúde.

Segundo Pereira et. al. (2013) as práticas de educação em saúde para adolescentes no âmbito escolar através do Programa de saúde na escola (PSE), são pouco efetivas, pois contempla apenas o estudante e não o grupo familiar, necessitando-se sensibilizar os pais ou responsáveis para a importância de uma cobertura vacinal adequada para doenças preveníveis por imunização, devendo-se ainda respeitar a peculiaridade de cada família.

Programa de vacinação são medidas seguras em saúde pública que no Brasil vem despontando como procedimento que atinge excelentes resultados, a partir da vacinação de rotina e de massa, dos grupos vulneráveis. Há o investimento em imunobiológicos, hoje perfazendo 44 disponíveis para a população de forma gratuita, permitindo excelente resultados; algumas doenças preveníveis por imunização foram erradicadas, como exemplo a Poliomielite, a rubéola congênita tem sido controlada e o sarampo teve o último caso relatado em 2000. (BRASIL, 2014).

A compreensão da importância de elaborar um programa de imunização que reduzisse a morbimortalidade por meio da vacinação em grandes grupos de indivíduos saudáveis, oferece ao indivíduo o mínimo de risco, para que não haja Eventos 
Adversos pós-vacinação (EVPV), que foi um dos motivos apontados pelo adolescente para não adesão conforme estudo de Domingues e Teixeira (2012).

Nota-se que há uma predileção para a discussão sobre a efetividade da vacinação de massa ou campanhas multivacinação, porém os dados consolidados no SI-PNI, disponibilizam dados tanto de vacinação de rotina quanto das campanhas, podendo ser encontrados valores de CV acima de 100\% em municípios menores de 20 mil habitantes.

Apesar de ser inegável a importância da busca ativa na comunidade para manutenção da CV, o conhecimento da população sobre o tema faz-se prioritário para a adesão a vacinas que ainda permanecem com baixas taxas de adesão.

Estudos que utilizaram amostras teve base populacional local sendo, a cobertura vacinal no Brasil efetivamente trabalhado por apenas 02 autores, ainda que com foco no público em geral e recorte para o público na faixa de 10 a 19 anos (tabela 2).

O fato de haver na literatura poucas pesquisas especificamente voltadas para a CV em adolescentes no Brasil como um todo, suscita a importância de realizarem-se pesquisas multicêntricas com amostragem probabilística aleatória, segundo Oliveira (2009) ainda que sejam menos efetivos, estes estudos probabilísticos estratificados, têm menos precisão, mas, permite custo e benefício satisfatório para adequação da amostra para o público adolescente, assim poderíamos estimar a real PA por estratos de 10 a 14 anos e 15 a 19 anos no Brasil, e compreender como alcançar a cobertura ideal de $95 \%$ também nestas faixas.

\section{CONSIDERAÇÕES FINAIS}

Com a revisão sobre cobertura vacinal dos adolescentes brasileiros, buscou-se tratar de um tema relevante para saúde pública brasileira, pois, para o Brasil pode contribuir direcionar a atenção básica para a cobertura vacinal deste grupo vulnerável e suscitar a participação popular como ferramenta para melhoria das políticas públicas para imunização dos adolescentes. 
Os fatores associados a não vacinação nessa faixa, são controversos, porém há unanimidade entre os autores quando apontam que para alcançar os adolescentes, é necessário que gestores, profissionais de saúde e família encontrem o denominador comum para planejar ações estratégicas de vacinação na rede pública, devendo-se estabelecer um debate saudável e democrático sobre os benefícios da imunização e manutenção de coberturas vacinais adequadas.

O destaque brasileiro deve ao sucesso do PNI nas faixas menores de 10 anos, justifica o olhar da comunidade internacional para a Proporção de abandono (PA) nas faixas de 10 a 19 anos, sobretudo de 15 a 19 anos; ratificando a pouca compreensão dos fatores associados a não adesão desse público apesar dos esforços do Ministério da Saúde brasileiro.

\section{REFERENCIAS}

BRASIL. Secretaria de vigilância em Saúde. Departamento de Vigilância epidemiológica. Programa Nacional de Imunização (PNI): $\mathbf{4 0}$ anos: Livro. Brasília: DF, 2013.236p.(coletânea)

BRASIL. Lei № 6259. Dispõe sobre a organização das ações de Vigilância Epidemiológica, sobre o Programa Nacional de Imunizações, estabelece normas relativas à notificação compulsória de doenças, e dá outras providências. Brasília: DF: Senado Federal.1975. Disponível em: <http://www.planalto.gov.br/ccivil_03/leis/L6259.htm>.Acesso em:10 abr.2016.

BRASIL. Lei № 78231/76. Regulamenta a lei 6259, de 30 de outubro de 1975, que dispõe sobre a organização das açõs de vigilância epidemiológica, sobre o Programa nacional de imunizações, estabelece normas relativa a notificação compulsória de doenças, e dá outras providências. Brasilia: DF. Senado Federal. 1976.

Disponível em:

http://legislacao.planalto.gov.br/legisla/legislacao.nsf/Viw_Identificacao/DEC\%2078.2 31-1976?OpenDocument> Acesso em 10 abr.2016. 
BRASIL. Ministério da Saúde. Secretaria de atenção à saúde Departamento de atenção básica. Caderno de atenção básica n. 24: Programa saúde na escola: livro.1. ed. Brasília: DF, 2009, 96p. (coletânea) ISBN 978-85-334-1644-4. Disponível em <http://dab.saude.gov.br/docs/publicacoes/cadernos_ab/abcad24.pdf> Acesso em 23 mai.2016.

BRASIL. Ministério da Saúde. Secretaria de vigilância em saúde. Departamento de Vigilância das doenças transmissíveis. Normas e procedimentos para vacinação: manual. Brasília: DF, 2014.176p. ISBN 978-85-334-1644-4

DOMINGUES, Carla Magda Allan S; TEIXEIRA, Antônia Maria da Silva. Coberturas vacinais e doenças imunopreveníveis no Brasil no período 1982-2012: avanços e desafios do Programa Nacional de Imunizações. Epidemiol. Serv. Saúde, Brasília , v. 22, n. 1, p. 9-27, mar. 2013 . Disponível em <http://scielo.iec.pa.gov.br/scielo.php?script=sci_arttext\&pid=S1679$49742013000100002 \&$ Ing=pt\&nrm=iso $>$. Acesso em 07mai. 2016.

DOMINGUES, Carla Magda Allan S.; TEIXEIRA, Antonia Maria da Silva; CARVALHO, Sandra Maria Deotti. National immunization program: vaccination, compliance and pharmacovigilance. Rev. Inst. Med. trop. S. Paulo, São Paulo, v. 54, supl. 18, p. 22-27, Oct. $2012 \quad$ Disponível em<http://www.scielo.br/scielo.php?script=sci_arttext\&pid=S0036$46652012000700009 \&$ Ing=en\&nrm=iso $>$. Acesso em 26 jun. 2016.

DOMINGUES, C.M.A.S.; TEIXEIRA, A.M.S. ; CARVALHO, S.M.D. - National immunization program: vaccination, compliance and pharmacovigilance. Rev. Inst.Med. Trop. Sao Paulo,p.54(Suppl. 18), 2012.

FRANCISCO, Priscila Maria Stolses Bergamo et al . Vacinação contra hepatite B em adolescentes residentes em Campinas, São Paulo, Brasil. Rev. bras. epidemiol., São Paulo , v. 18, n. 3, p. 552-567, Set. 2015 . Disponível em <http://www.scielo.br/scielo.php?script=sci_arttext\&pid=S1415790X2015000300552\&Ing=en\&nrm=iso >. Acesso em 07 mai. 2016 
FREITAS, Angela Carvalho; OKANO, Valdir; PEREIRA, Júlio Cesar Rodrigues. Pertussis booster vaccine for adolescents and young adults in São Paulo, Brazil. Rev. Saúde Pública, São Paulo , v. 45, n. 6, p. 1162-1171, Dec. 2011 Disponível em $<$ http://www.scielo.br/scielo.php?script=sci_arttext\&pid=S0034$89102011000600008 \&$ Ing=en\&nrm=iso >. Acesso em 26 jun. 2016.

FRANCISCO, Priscila Maria Stolses Bergamo et al . Vacinação contra rubéola em mulheres em idade reprodutiva no Município de Campinas, São Paulo, Brasil. Cad. Saúde Pública, Rio de Janeiro , v. 29, n. 3, p. 579-588, Mar. 2013. Disponível em<http://www.scielo.br/scielo.php?script=sci_arttext\&pid=S0102-

$311 X 2013000300015 \&$ Ing=en\&nrm=iso $>$. Acesso em em26 jun. 2016.

GOMES, K.R.O. Roteiro para elaboração de Projeto de Pesquisa: recomendações sobre ABNT. [s.n.], 2016. 02 p.

MASCARENHAS, Márcio Dênis Medeiros. Publicação eletrônica. Comunicação científica em Saúde Pública. Mensagem recebida por <mdm.mascarenhas@gmail.com> em 05 mai.2016.

OLIVEIRA, A. Gouveia de. Bioestatística, Epidemiologia e Investigação: teoria e aplicações. 1 ed. Portugal: Lisboa, 2009. 255 p. ISBN978-972-757-558-9

RODRIGUES, Malvina Thais Pacheco. Publicação eletrônica. Trabalho sore produção de artigo. Mensagem recebida de <malvinat@gmail.com>em 23 jun. 2016.

RODRIGUES, Malvina Thais Pacheco. Como fazer uma Revisão Integrativa, marc. A jun. 2016. 05 f. notas de aula. Mimeografado.

SILVA JUNIOR, Jarbas Barbosa da. 40 anos do Programa Nacional de Imunizações: uma conquista da Saúde Pública brasileira. Epidemiol. Serv. Saúde, Brasília , v. 22, n. 1, p. 7-8, mar. 2013 .Disponível em $<$ http://scielo.iec.pa.gov.br/scielo.php?script=sci_arttext\&pid=S1679$49742013000100001 \&$ Ing=pt\&nrm=iso>. acesso em 07 mai. 2016. 
Enviado: Outubro, 2020.

Aprovado: Outubro, 2020. 